\title{
Hydrocephalus and hypothalamic involvement in pediatric patients with craniopharyngioma or cysts of Rathke's pouch: impact on long-term prognosis
}

\author{
A M M Daubenbüchel 1,2, A Hoffmannn ${ }^{1}$, U Gebhardt ${ }^{1}$, M Warmuth-Metz ${ }^{3}$, \\ A S Sterkenburg ${ }^{1,2}$ and H L Müller ${ }^{1}$ \\ ${ }^{1}$ Department of Pediatrics, Klinikum Oldenburg, Medical Campus University Oldenburg, Rahel-Straus-Strasse 10, \\ 26133 Oldenburg, Germany, ${ }^{2}$ University of Groningen, Groningen, The Netherlands and ${ }^{3}$ Department of \\ Neuroradiology, University Hospital, Würzburg, Germany
}

\author{
Correspondence \\ should be addressed \\ to H L Müller \\ Email \\ mueller.hermann@ \\ klinikum-oldenburg.de
}

\begin{abstract}
Objective: Pediatric patients with sellar masses such as craniopharyngioma (CP) or cyst of Rathke's pouch (CRP) frequently suffer disease- and treatment-related sequelae. We analyzed the impact and prognostic relevance of initial hydrocephalus (HY) and hypothalamic involvement (HI) on long-term survival and functional capacity (FC) in children with CP or CRP. Subjects and methods: Using retrospective analysis of patient records, presence of initial HY or HI was assessed in 177 pediatric patients (163 CP and 14 CRP). Twenty-year overall survival (OS) and progression-free survival (PFS), FC, and BMI were analyzed with regard to initial $\mathrm{HY}$, degree of resection, or $\mathrm{HI}$.

Results: Of the 177 patients, 105 patients (103/163 CP and 2/14 CRP) presented with initial HY and 96 presented with HI. HY at diagnosis was associated $(P=0.000)$ with papilledema, neurological deficits, and higher BMI at diagnosis and during followup. OS, PFS, and FC were not affected by HY at initial diagnosis. HI at diagnosis (96/177) had major negative impact on longterm prognosis. Sellar masses with $\mathrm{HI}$ were associated with lower OS $(0.84 \pm 0.04 ; P=0.021)$, lower $\mathrm{FC}(P=0.003)$, and higher $\mathrm{BMI}$ at diagnosis and last follow-up $(P=0.000)$ when compared with sellar masses without $\mathrm{HI}(\mathrm{OS}$ : $0.94 \pm 0.05)$. PFS was not affected by $\mathrm{HI}$ or degree of resection.

Conclusions: Initial HY has no impact on outcome in patients with sellar masses. OS and FC are impaired in survivors presenting with initial HI. PFS is not affected by HY, HI, or degree of resection. Accordingly, gross-total resection is not recommended in sellar masses with initial $\mathrm{HI}$ to prevent further hypothalamic damage.
\end{abstract}

\section{Introduction}

Childhood craniopharyngiomas (CPs) are sellar embryogenic malformations of low-grade histological malignancy and low incidence (1). Despite high survival rates (92\%), the quality of survival is frequently impaired due to sequelae caused by hypothalamic obesity $(1,2,3,4)$. The pathogenic mechanisms underlying hypothalamic obesity are complex and multifactorial (5). Weight gain results from damage to the ventromedial hypothalamus, which leads, variously, to a low resting metabolic rate, autonomic imbalance, endocrine deficits, reduced physical activity, and insomnia (6). Owing to embryogenic origin, cysts of Rathke's pouch (CRP) are closely related to CP. Recent reports $(7,8)$ have also demonstrated high overall and event-free survival rates in patients with CRP.

With the aid of imaging studies, recent reports have indicated that the degree of obesity of patients with sellar masses is positively correlated with the degree and extent of hypothalamic damage $(7,8,9,10,11)$. Despite the 
availability of promising therapeutic approaches, it must be emphasized that there is currently no pharmacological therapy for hypothalamic obesity that has been shown to be effective in controlled studies. Surgical strategies to preserve hypothalamic integrity are mandatory for the prevention of hypothalamic obesity (1).

Based on reports in the literature $(12,13,14,15,16)$, it is not clear whether the presence of hydrocephalus (HY) constitutes a prognostic factor for long-term outcome in pediatric patients with sellar masses. The present retrospective study assessed the impact of HY, degree of resection, and tumor location at the time of diagnosis on survival and outcome in a large cohort of long-term survivors of these sellar masses.

\section{Subjects and methods}

In pediatric patients with sellar masses (CP or CRP) diagnosed between 1966 and 2001 and recruited in our cross-sectional study known as HIT Endo $(17,18)$ (Fig. 1), the presence or absence of initial $\mathrm{HY}$ at the time of diagnosis was assessed based on magnetic resonance imaging (MRI) and/or computed tomography (CT) of sufficient quality (Fig. 2A and B). Out of 505 patients recruited in the German Craniopharyngioma Registry (485 CP patients plus 20 patients with CRP), 177 patients were included in our study and 328 patients were excluded. Criteria for inclusion are as follows: i) diagnosis of childhood-onset CP between 1966 and 2001 and ii) availability of appropriate imaging for referenceconfirmed presence of $\mathrm{HY}$ at the time of diagnosis.

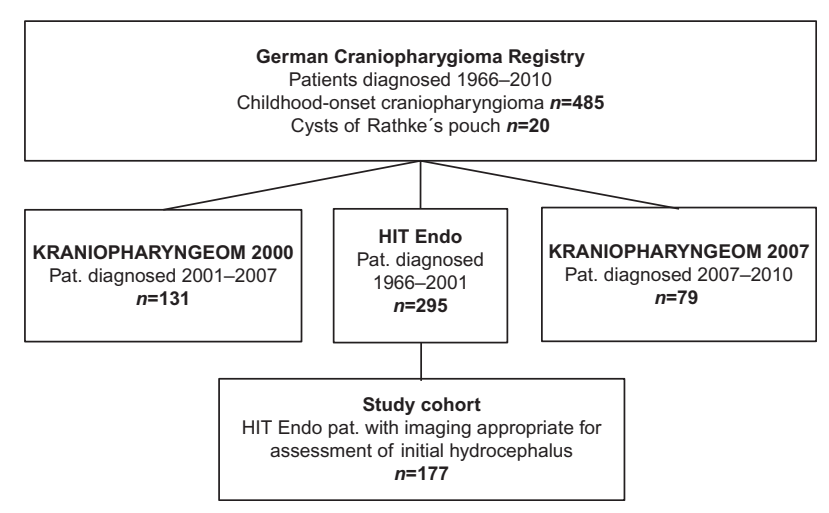

\section{Figure 1}

Selection criteria for the study cohort of 177 patients diagnosed with childhood-onset craniopharyngioma between 1966 and 2001, in which appropriate initial imaging for reference assessment of hydrocephalus was available at the time of study.
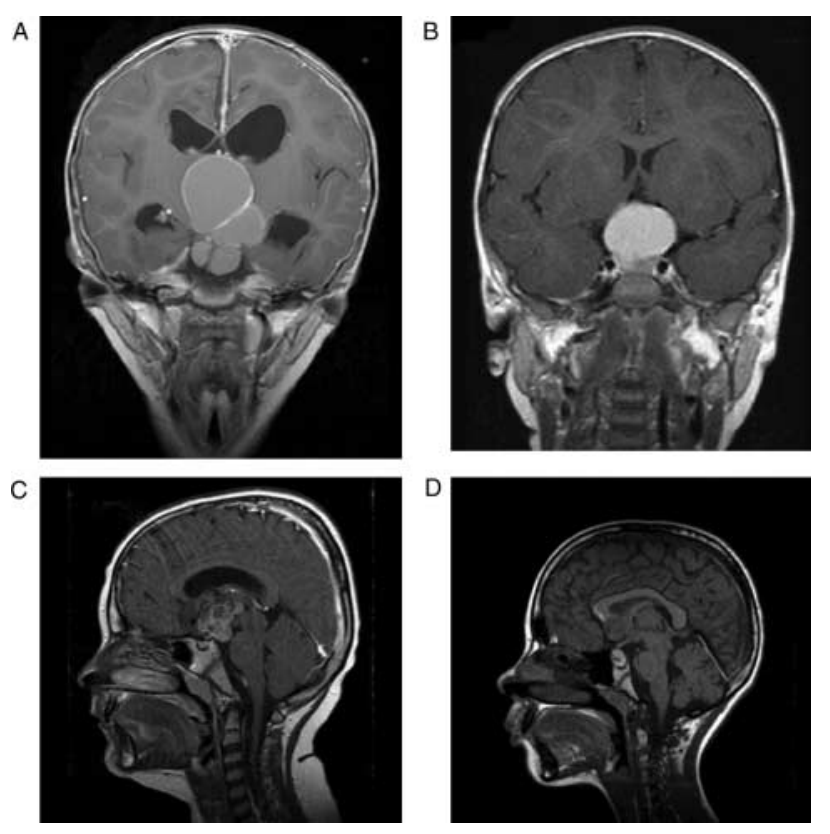

\section{Figure 2}

Magnetic resonance images (MRIs) of pediatric patients with sellar masses: childhood-onset craniopharyngioma patients presenting with hydrocephalus $(A)$ and without hydrocephalus (B), and with hypothalamic involvement (C) and without hypothalamic involvement (D). (C) and (D) are reproduced from Muller HL, Gebhardt U, Teske C, Faldum A, Zwiener I, WarmuthMetz M, Pietsch T, Pohl F, Sorensen N \& Calaminus G. Postoperative hypothalamic lesions and obesity in childhood craniopharyngioma: results of the multinational prospective trial KRANIOPHARYNGEOM 2000 after 3-year follow-up. European Journal of Endocrinology 2011165 17-24 (8) with permission from the European Society of Endocrinology.

Of the 328 excluded patients, 210 were diagnosed between 2001 and 2010 and in the remaining 118 patients no appropriate imaging for the reference assessment of $\mathrm{HY}$ was available. This is due to the fact that some of the patients in our multicenter registry were diagnosed as early as in the 1960s. A neuroradiologist (M W-M) performed blind MRI evaluations, and tumor volumes were calculated according to methods described previously (8). Initial HY was confirmed in 103 out of 163 CP patients and in two out of 14 patients with CRP. Diagnoses of CP and CRP were made at a median age of 8.8 years, ranging from 1.5 to 25.2 years-of-age in 177 patients (85 females and 92 males). The histological diagnoses were confirmed by pathological reference assessment in all cases. The median follow-up interval was 15.7 years in $\mathrm{CP}$ and 4.2 years in patients with CRP. 
In our cross-sectional study, long-term survivors were analyzed regarding the impact of initial $\mathrm{HY}$, degree of resection, and $\mathrm{HI}$ (Fig. 2C and D) on clinical presentation at diagnosis, survival rates, quality of life (QoL) (functional capacity (FC)), and BMI during long-term follow-up. In two patients, long-term follow-up data were not available. Initial imaging was reference assessed for HY or hypothalamic tumor involvement as part of the HIT Endo trial.

Body height was measured using a stadiometer. Body weight was evaluated by calculating the body mass index $\left(\mathrm{BMI}=\right.$ weight $(\mathrm{kg}) /$ height $\left.^{2}\left(\mathrm{~m}^{2}\right)\right)$ and expressing the BMI as an SDS using the references of Rolland-Cachera et al. (19). BMI SDS was evaluated at the time of diagnosis and at the time of last visit.

The German daily life ability scale Fertigkeitenskala Münster-Heidelberg (FMH) was used for self-assessment of QoL (FC) $(20,21,22)$ in patients with tumors of the sellar region. The FMH measures the capability for routine actions, with 56 items such as 'can walk without aid' or 'earns money' (Supplementary Table 1, see section on supplementary data given at the end of this article). It was normalized with 971 persons (45.5\% female), aged between 0 and 102 years, resulting in age-dependent percentiles (20). The test-retest reliability coefficient was 0.99 . The validity was tested in ten brain tumor patients: there was good agreement with IQ $(r=0.7)$ and semiquantitative assessments performed by a physician $(P<0.001)$. The average time for answering the FMH questionnaire was $4.5 \mathrm{~min}$ in first-time users $(18,23)$.

Statistical analyses were performed using SPSS 22.0 (SPSS, Inc.). For comparison of two independent groups for a continuous variable, the Mann-Whitney $U$ test was used. For comparison of different groups for categorical variables, the $\chi^{2}$-test was used. A $P$ value of $<0.05$ was chosen as being statistically significant. Overall survival (OS) and progression-free survival (PFS) rates were estimated by the Kaplan-Meier method.

This study was approved by the local standing committee on ethical practices and written parental and/or patient consent was obtained in all cases.

\section{Results}

The study cohort (177 patients with appropriate imaging for assessment of $\mathrm{HY}$ ) was similar in terms of baseline characteristics (sex, age at diagnosis, and age at last visit) when compared with the cohort of 118 patients excluded from our study due to a lack of appropriate imaging for reference assessment of HY at the time (1966-2001) of diagnosis (data not shown). The excluded 118 patients were diagnosed based on histology (58\%) or imaging results (MRI and/or CT). However, primary imaging scans in these 118 excluded patients were either of nonsufficient quality for reference assessment of HY or not available at the time of study.

The OS rate was $0.88 \pm 0.03$ (Fig. 3A) and the PFS rate was $0.68 \pm 0.07$ (Fig. 3B) in the study cohort of 177 pediatric patients with CP or CRP. Of the 177 patients, 105 (103/163 CP and 2/14 CRP) presented with HY at initial diagnosis (Table 1). Patients with HY were diagnosed at a younger age (median age: 7.2 years; range: $1.5-25.2$ years) when compared with patients without HY (median age: 10.5 years; range: $0.1-21.0$ years $)(P=0.001)$. The followup interval after diagnosis was longer in HY patients
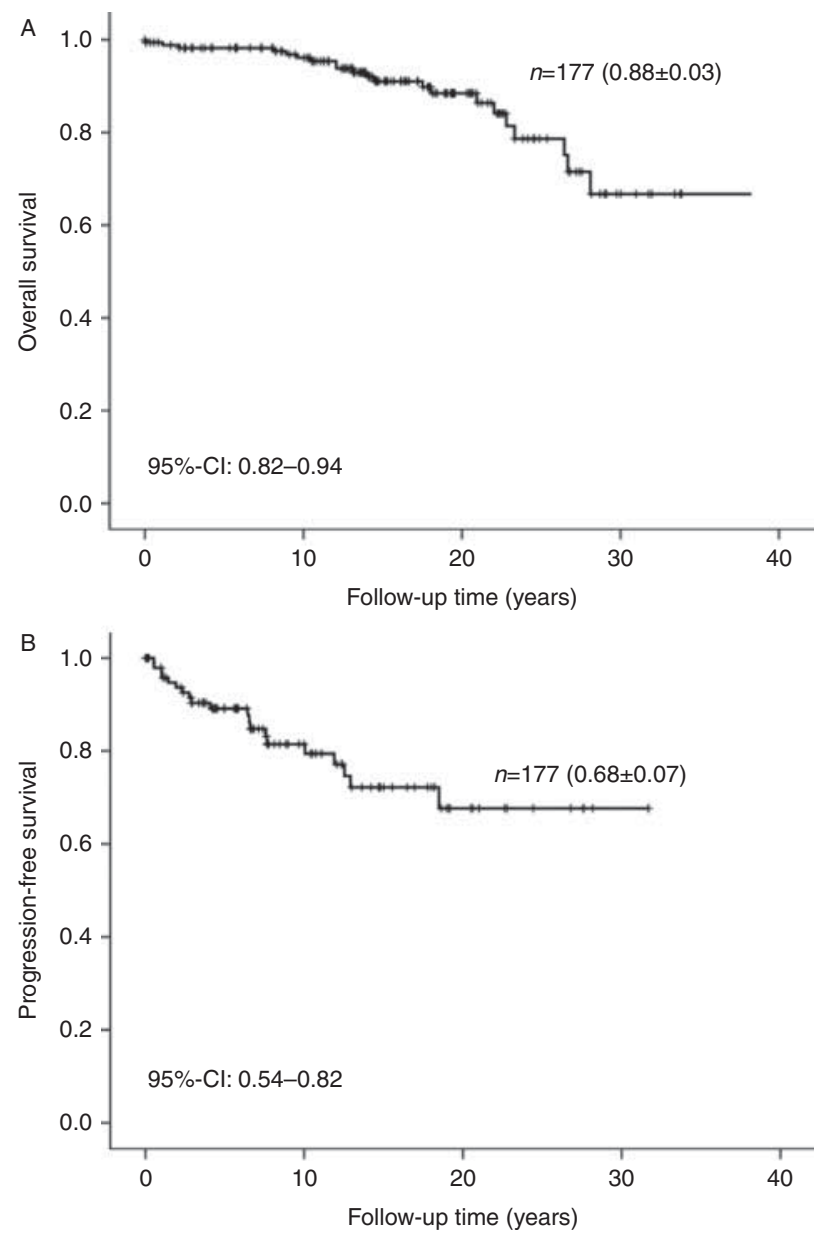

\section{Figure 3}

Twenty-year overall survival (A) and 20-years progression-free survival (PFS) rates (B) of 177 pediatric patients with sellar masses ( 163 childhood-onset craniopharyngioma and 14 cysts of Rathke's pouch) diagnosed between 1966 and 2001 and recruited in HIT Endo. 


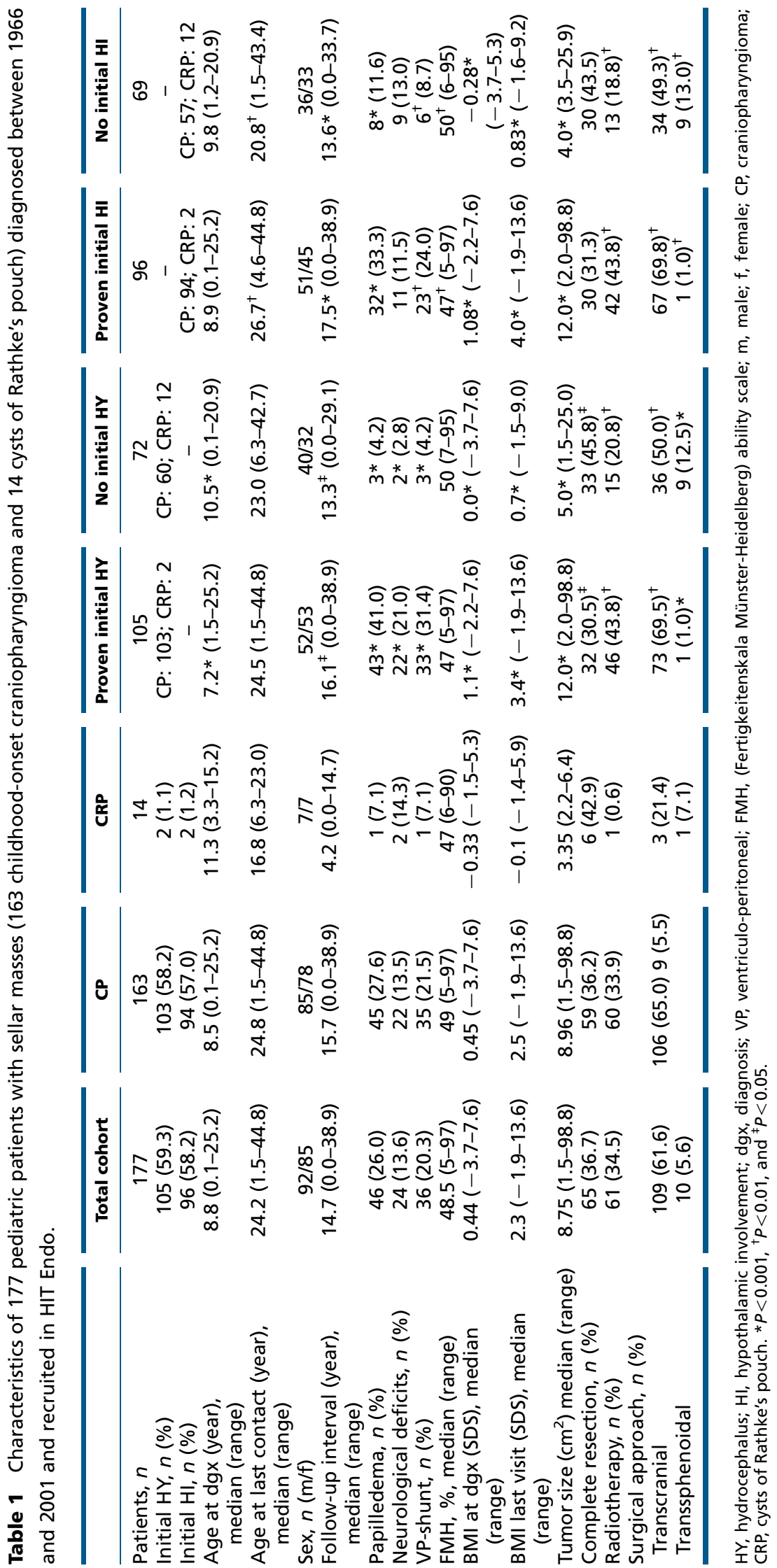


(median follow-up: 16.1 years) when compared with patients without HY (median follow-up: 13.3 years) $(P=0.014)$. No differences between patients with and without HY were detectable regarding sex distribution. HY at diagnosis was significantly associated with papilledema (41\%; $P=0.000$ ), neurological deficits such as seizures, palsy, and nystagmus (21\%; $P=0.000)$, higher BMI SDS at diagnosis (median BMI: +1.1 s.D.; range: -2.2 to +7.6 S.D.; $P=0.001$ ) and during follow-up (median BMI at last visit: +3.4 s.D.; range: -1.9 to +13.6 s.D.; $P=0.000$ ), and the insertion of a ventriculo-peritoneal (VP)-shunt (31\%; $P=0.000$ ). OS (Figs $4 \mathrm{~A}$ and $5 \mathrm{~A}$ ), PFS (Figs $4 \mathrm{~B}$ and $5 \mathrm{~B}$ ), and long-term FC (FMH ability scale) (Table 1 ) were not significantly related to HY or surgical degree of resection at initial diagnosis respectively. A complete resection was achieved in 65 out of 177 patients (36.7\%), the resection was incomplete in 83 out of 177 patients (46.9\%), and the degree of resection could not be sufficiently assessed in 29 out of 177 patients (16.4\%). Complete resections were performed more frequently $(P=0.025)$ in patients without HY than in patients with HY (Table 1). Long-term FC (FMH ability scale) was similar $(P=0.164)$ after complete vs incomplete surgical resection (data not shown).

We also analyzed the impact of hypothalamic involvement (HI) at the time of diagnosis on initial clinical presentation, survival rates, FC, and BMI in this cohort of 177 long-term $\mathrm{CP}$ and $\mathrm{CRP}$ survivors. $\mathrm{HI}$ at diagnosis was confirmed in 96 of the 177 patients (94/163 CP and 2/14 CRP). Patients with and without HI were similar with regard to sex distribution, age at diagnosis, and the rate of neurological deficits at the time of diagnosis (Table 1). Patients with HI were assessed at a longer follow-up interval after diagnosis (median follow-up interval: 17.5 years) when compared with patients without HI (median follow-up interval: 13.6 years) $(P=0.001)$. HI was associated with a higher rate of papilledema $(33 \%, P=0.000)$ and insertion of a VP-shunt (24\%; $P=0.011)$.

$\mathrm{HI}$ had major negative impact on long-term prognosis. Sellar masses with $\mathrm{HI}$ were associated with lower OS $(0.84 \pm 0.04 ; P=0.021)$ (Fig. $6 \mathrm{~A}$ ), lower FC during followup (FMH percentile: median 47; range: 5-97, $P=0.003$ ), and higher BMI SDS at diagnosis (median BMI: +1.08 s.D.; range: -2.2 to +7.6 s.D.; $P=0.000$ ) and at last follow-up visit (median BMI: +4.0 s.D.; range: -1.9 to +13.6 s.D.; $P=0.000)$ when compared with sellar masses without $\mathrm{HI}$ (OS: 0.94 \pm 0.05 ; FMH percentile: median 50, range: 6-95; median BMI at diagnosis: -0.28 s.D., range: -3.7 to +5.3 s.D.; median BMI at last follow-up: +0.83 s.D., range: -1.6 to +9.2 s.D.). Similar to HY, PFS was not significantly related to $\mathrm{HI}$ at initial diagnosis (Fig. 6B).
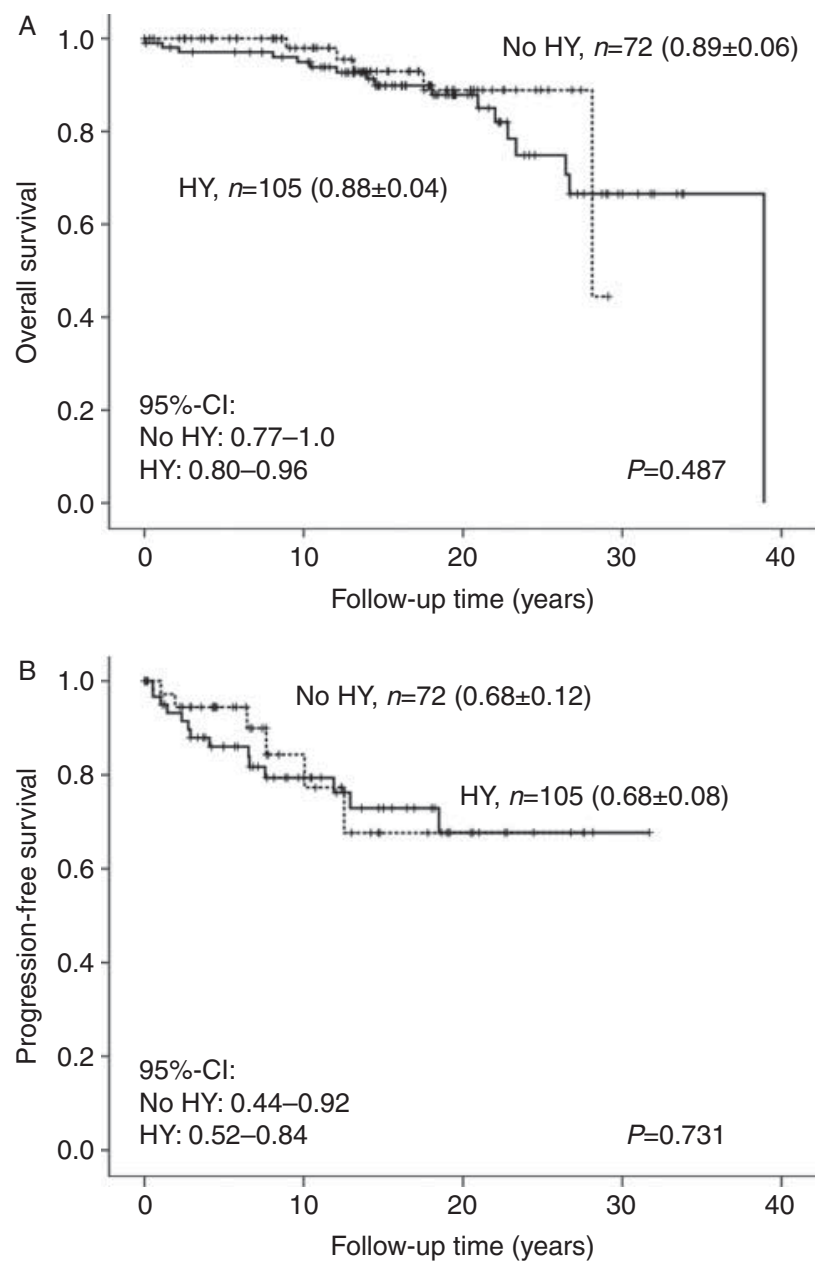

\section{Figure 4}

Twenty-year overall survival (A) and 20-years progression-free survival (PFS) rates (B) of 177 pediatric patients with sellar masses ( 163 childhood-onset craniopharyngioma and 14 cysts of Rathke's pouch) diagnosed between 1966 and 2001 and recruited in HIT Endo related to the neuroradiological findings of hydrocephalus (HY) at the time of primary diagnosis.

Rates of irradiation (Table 1$)$ were higher $(P=0.002$; $P=0.004$ respectively) in patients with HY (44\%) and HI $(44 \%)$ at initial diagnosis when compared with patients without HY (21\%) or HI (19\%). This observation has to be interpreted with regard to larger tumor sizes in patients with HY or HI ( $P=0.001 ; P=0.002$ respectively), potentially necessitating more intensive treatment.

Out of 177 patients of the study cohort, 23 patients died. Causes of death could be evaluated in 14 out of 23 deceased patients. Out of 14 mortality cases with a known cause of death, six died due to endocrinopathies (four acute adrenal insufficiency and two salt water imbalances 

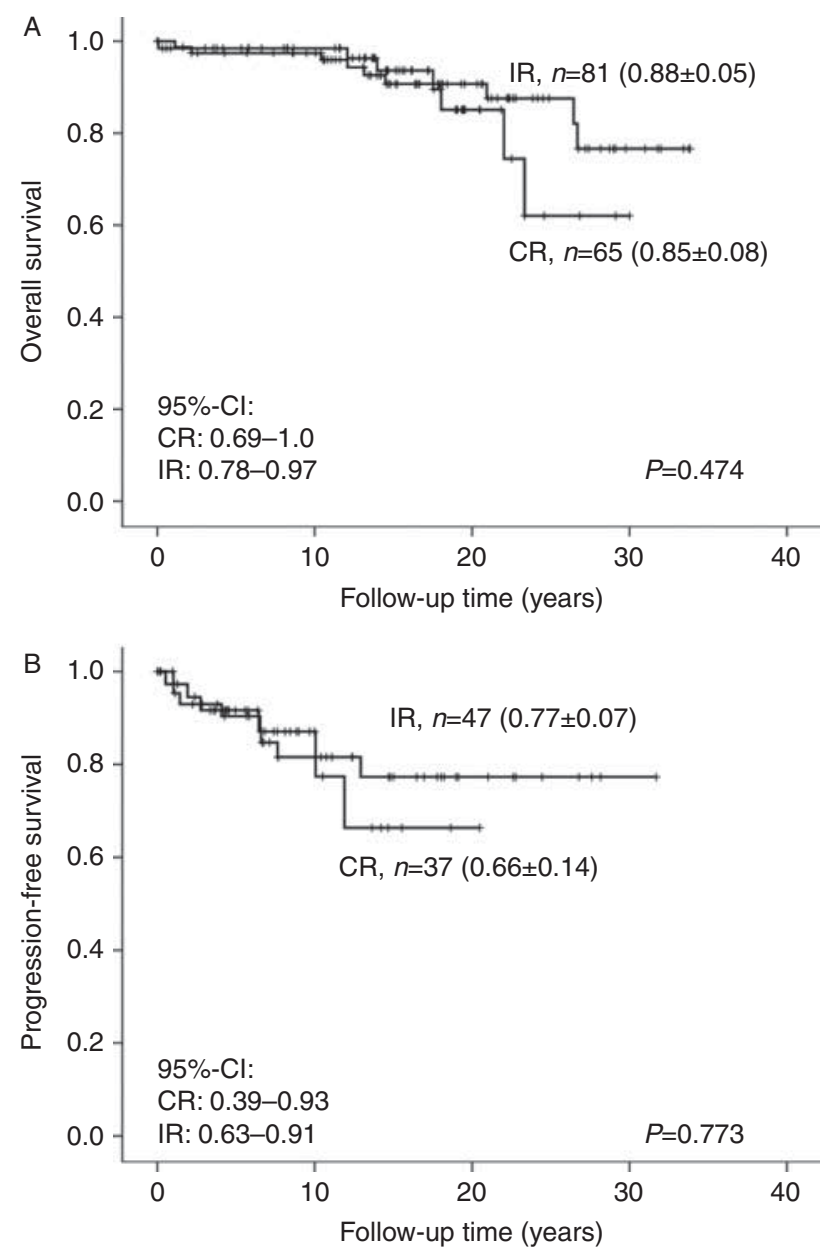

\section{Figure 5}

Twenty-year overall survival (A) and 20-years progression-free survival (PFS) rates (B) of 177 pediatric patients with sellar masses (163 childhood-onset craniopharyngioma and 14 cysts of Rathke's pouch) diagnosed between 1966 and 2001 and recruited in HIT Endo related to the degree of surgical resection at primary diagnosis. CR, complete resection; IR, incomplete resection.

due to diabetes insipidus). Out of 14 mortality cases with a known cause of death, six died due to tumor progression, two due to vascular complications, one due to liver cirrhosis, and two committed suicide.

\section{Discussion}

Owing to tumor location, sellar masses such as childhood CP and CRP are associated with high rates (41-54\%) of $\mathrm{HY}$ at the time of initial presentation $(16,24,25)$. In our cohort, we found a $59 \%$ rate, supporting these findings (Table 1 ).

In the CP study of Yasargil et al. (12), outcome (evaluated by deterioration of patient's general condition, dependence, endocrine replacement, and psycho-organic syndrome) was significantly compromised in patients with large tumors or HY or in those who underwent second or subsequent craniotomy for recurrence or uncontrolled growth of the original tumor. De Vile et al. (26) suggested that severe HY, occurrence of intraoperative complications (vascular or frontal lobe trauma), and young age at presentation were predictors of poor longterm outcome. In the CP series reported by Duff et al. (27), factors associated with poor outcome were also HY, visual deterioration or papilledema at presentation, and tumor calcification and/or adhesiveness to surrounding neurovascular structures.
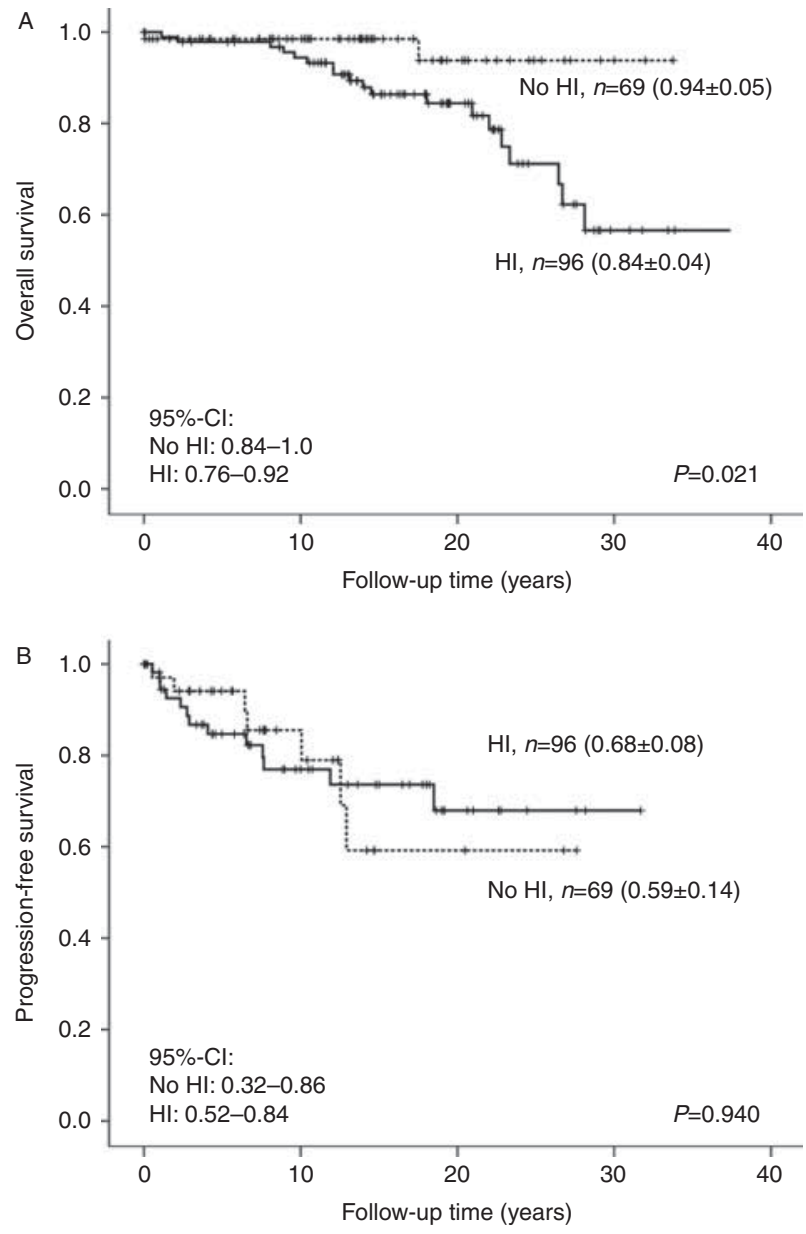

\section{Figure 6}

Twenty-year overall survival $(A)$ and 20-years progression-free survival (PFS) rates (B) of 177 pediatric patients with sellar masses (163 childhood-onset craniopharyngioma and 14 cysts of Rathke's pouch) diagnosed between 1966 and 2001 and recruited in HIT Endo related to the neuroradiological findings of hypothalamic involvement $(\mathrm{HI})$ at the time of primary diagnosis. 
CPs, although histologically benign, are associated with significant mortality, with reported overall mortality rates three to five times higher than those of the general population $(28,29)$. The OS rates (which reflect effect of multiple treatments) described in an exclusively pediatric series ranged from 83 to $96 \%$ at 5 years $(14,15,17,30,31,32$, $33)$ and 65 to $100 \%$ at 10 years $(15,26,30,31,32,34,35,36$, $37,38,39,40,41)$, averaging $62 \%$ at 20 years (42). In adults or a broad age-range population (adults and children) series, the OS rates ranged from 54 to $96 \%$ at 5 years $(13,16,25,29$, $32,43,44,45,46), 40$ to $93 \%$ at 10 years $(13,16,25,28,29$, $32,43,44,45,46)$, and 66 to $85 \%$ at 20 years $(29,45,46)$. The lower limits of survival rates usually reflected data from earlier series that occurred before modern advances in microsurgery, neuroimaging, and radiotherapy.

What remains unclear is whether the age at diagnosis represents a survival prognostic factor because some studies have demonstrated that the youngest patients have better survival rates $(28,32,44)$, others have found better outcome in older patients $(12,46)$, whereas still other studies report no difference between pediatric and adult populations $(13,16,45,47)$. The role of sex as a prognostic factor is not established; some authors report a higher mortality among females $(28,29)$, but others have not found any sex differences $(13,15,16)$. One of the two studies reporting higher mortality rates in females suggested a possible role of estrogen deficiency (29), but the other study did not consider that unsupplemented gonadal insufficiency had a significant impact on enhanced mortality (28).

Disease-related mortality can occur even many years after treatment. Causes of late mortality include those directly related to the tumor or its treatment such as progressive disease with multiple recurrences, chronic hypothalamic insufficiency, hormonal deficiencies, cerebrovascular disease, and seizures $(26,38,40,48)$. Other disease-related causes of mortality have been described, including decreased mineral bone density and non-alcoholic steatohepatitis, leading to liver cirrhosis in some cases $(38,40)$. A recent review has reported substantial long-term morbidity with hypopituitarism, increased cardiovascular risk, hypothalamic damage, visual and neurological deficits, reduced bone health, and reduction in QoL and cognitive function (49). The standardized overall mortality rate varies from 2.88 to 9.28 in cohort studies covered in this review. According to the review, patients with childhood $\mathrm{CP}$ have a threeto 19-fold higher cardiovascular mortality in comparison with the general population, and female childhood CP patients have an even higher risk (46).
Tumor size is likely to be a prognostic factor because increased survival rates have been shown in tumors with a diameter smaller than $3 \mathrm{~cm}$ (47). Several studies have described a more favorable prognosis when tumors lack calcification, especially in adult CP patients $(12,47)$, although no specific pathological feature predicted survival in childhood CP patients (14). In other studies, neither tumor histology $(16,47)$ nor tumor location $(15,16)$ had prognostic importance.

It is not clear whether the presence of HY constitutes a prognostic factor because both increased mortality (12) and lack of association with mortality have been reported $(13,14,15,16)$. Our retrospective analyses of the thus far largest published cohort of long-term survivors of childhood-onset CP and CRP show that HY at diagnosis was not associated with reduced survival rates and impaired FC during long-term follow-up, supporting previous reports $(13,14,15,16)$. Our analyses of the prognostic relevance of initial $\mathrm{HI}$ as a risk factor for reduced QoL (FC) in longterm survivors are also in line with previous reports $(7,8$, $18,50,51)$, although these previous reports were mainly based on shorter follow-up evaluations. Our study shows for the first time that long-term survival rates (i.e., 20 years after diagnosis) in patients with CP or CRP were significantly impaired when initial HI was detectable. Furthermore, long-term FC was shown to be impaired when initial $\mathrm{HI}$ was detectable in patients with CP or CRP.

The degree of surgical resection had no significant impact on long-term outcome in terms of OS, PFS, and FC, indicating that gross-total resections have no clinical advantage with regard to recurrence rates and QoL. Hoffmann et al. (11) analyzed changes in surgical strategy by comparing our cohort treated during the period of 2001-2007 with our more recent cohort treated during the period of 2007-2012. The authors observed a change toward less aggressive surgical strategies (gross-total resections) during the last 15 years.

The results of our study are limited due to retrospective analysis and, as indicated, some observations are speculative at this point. The potential size of the cohort was also limited because appropriate documentation of MRI and/or CT for assessment of initial HY was available only in 177 out of 295 patients recruited in our HIT Endo Registry.

We conclude that initial HY at the time of diagnosis has no impact on survival and QoL in long-term survivors of CP and CRP. PFS appears not to be related to HY, HI, or the degree of surgical resection. However, OS and FC are significantly impaired in survivors presenting with $\mathrm{HI}$ at diagnosis. Accordingly, gross-total resection as a treatment strategy is not recommended in pediatric patients with 
sellar masses presenting with $\mathrm{HI}$ at initial diagnosis in order to prevent further hypothalamic damage and thereby hopefully increase long-term OS and FC. Longterm mortality is significantly related to endocrinopathies (2). Accordingly, treatment and follow-up of patients with CP and CRP should be performed by specialized and experienced multidisciplinary teams.

\section{Supplementary data}

This is linked to the online version of the paper at http://dx.doi.org/10.1530/ EJE-14-1029.

\section{Declaration of interest}

This manuscript was composed in the absence of any commercial or financial relationships that could be perceived as a potential conflict of interest.

\section{Funding}

H L Müller was supported by the German Childhood Cancer Foundation, Bonn, Germany.

\section{Author contribution statement}

A M M Daubenbüchel designed the cross-sectional study, evaluated patients' records, performed the statistical analyses, and wrote and reviewed the manuscript. A Hoffmann, MD, PhD, supervised data evaluation, performed plausibility controls, and reviewed the manuscript. U Gebhardt supervised statistical analyses, carried out the graphical work on figures, and reviewed the manuscript. Prof. M Warmuth-Metz, MD, reviewed $\mathrm{MRI}$ and computed tomographies of the patients as a neuroradiologist. A Sterkenburg participated in designing the study, evaluating patients' records, and writing and reviewing the manuscript. Prof. $\mathrm{H} \mathrm{L}$ Müller, MD, initiated the cross-sectional study, participated in evaluation of patients' records, supervised plausibility controls and statistical analyses, and reviewed the manuscript. H L Müller is the coordinator of the German Craniopharyngioma Registry and chairman of the HIT Endo trial.

\section{Acknowledgements}

The authors are grateful to Mrs Neff-Heinrich (Göttingen, Germany) for help in proofreading the manuscript.

\section{References}

1 Muller HL. Craniopharyngioma. Endocrine Reviews 201435 513-543. (doi:10.1210/er.2013-1115)

2 Muller HL. Consequences of craniopharyngioma surgery in children. Journal of Clinical Endocrinology and Metabolism 201196 1981-1991. (doi:10.1210/jc.2011-0174)

3 Muller HL. Childhood craniopharyngioma - current concepts in diagnosis, therapy and follow-up. Nature Reviews. Endocrinology 20106 609-618. (doi:10.1038/nrendo.2010.168)

4 Muller HL. Paediatrics: surgical strategy and quality of life in craniopharyngioma. Nature Reviews. Endocrinology 20139 447-449. (doi:10.1038/nrendo.2013.125)
5 Bereket A, Kiess W, Lustig RH, Muller HL, Goldstone AP, Weiss R, Yavuz Y \& Hochberg Z. Hypothalamic obesity in children. Obesity Reviews 201213 780-798. (doi:10.1111/j.1467-789X.2012.01004.x)

6 Lustig RH. The neuroendocrinology of childhood obesity. Pediatric Clinics of North America 200148 909-930. (doi:10.1016/S0031-3955(05)70348-5)

7 Muller HL, Gebhardt U, Faldum A, Warmuth-Metz M, Pietsch T, Pohl F, Calaminus G \& Sorensen N. Xanthogranuloma, Rathke's cyst, and childhood craniopharyngioma: results of prospective multinational studies of children and adolescents with rare sellar malformations. Journal of Clinical Endocrinology and Metabolism 201297 3935-3943. (doi:10.1210/jc.2012-2069)

8 Muller HL, Gebhardt U, Teske C, Faldum A, Zwiener I, WarmuthMetz M, Pietsch T, Pohl F, Sorensen N \& Calaminus G. Post-operative hypothalamic lesions and obesity in childhood craniopharyngioma: results of the multinational prospective trial KRANIOPHARYNGEOM 2000 after 3-year follow-up. European Journal of Endocrinology 2011165 17-24. (doi:10.1530/EJE-11-0158)

9 Puget S, Garnett M, Wray A, Grill J, Habrand JL, Bodaert N, Zerah M, Bezerra M, Renier D, Pierre-Kahn A et al. Pediatric craniopharyngiomas: classification and treatment according to the degree of hypothalamic involvement. Journal of Neurosurgery 2007 106 3-12. (PMID: 17233305)

10 Elowe-Gruau E, Beltrand J, Brauner R, Pinto G, Samara-Boustani D, Thalassinos C, Busiah K, Laborde K, Boddaert N, Zerah M et al. Childhood craniopharyngioma: hypothalamus-sparing surgery decreases the risk of obesity. Journal of Clinical Endocrinology and Metabolism 201398 2376-2382. (doi:10.1210/jc.2012-3928)

11 Hoffmann A, Warmth-Metz M, Gebhardt U, Pietsch T, Pohl F, Kortmann RD, Calaminus G \& Muller HL. Childhood craniopharyngioma - changes of treatment strategies in the trials KRANIOPHARYNGEOM 2000/2007. Klinische Pädiatrie 2014226 161-168. (doi:10.1055/s-0034-1368785)

12 Yasargil MG, Curcic M, Kis M, Siegenthaler G, Teddy PJ \& Roth P. Total removal of craniopharyngiomas. Approaches and long-term results in 144 patients. Journal of Neurosurgery 199073 3-11. (doi:10.3171/jns. 1990.73.1.0003)

13 Stripp DC, Maity A, Janss AJ, Belasco JB, Tochner ZA, Goldwein JW, Moshang T, Rorke LB, Phillips PC, Sutton LN et al. Surgery with or without radiation therapy in the management of craniopharyngiomas in children and young adults. International Journal of Radiation Oncology, Biology, Physics 200458 714-720. (doi:10.1016/S0360-3016(03)01570-0)

14 Fisher PG, Jenab J, Gopldthwaite PT, Tihan T, Wharam MD, Foer DR \& Burger PC. Outcomes and failure patterns in childhood craniopharyngiomas. Child's Nervous System 199814 558-563. (doi:10.1007/ s003810050272)

15 Tomita T \& Bowman RM. Craniopharyngiomas in children: surgical experience at Children's Memorial Hospital. Child's Nervous System 200521 729-746. (doi:10.1007/s00381-005-1202-9)

16 Karavitaki N, Brufani C, Warner JT, Adams CB, Richards P, Ansorge O, Shine B, Turner HE \& Wass JA. Craniopharyngiomas in children and adults: systematic analysis of 121 cases with long-term follow-up. Clinical Endocrinology 200562 397-409. (doi:10.1111/j.1365-2265.2005.02231.x)

17 Muller HL, Bueb K, Bartels U, Roth C, Harz K, Graf N, Korinthenberg R, Bettendorf M, Kuhl J, Gutjahr P et al. Obesity after childhood craniopharyngioma - German multicenter study on pre-operative risk factors and quality of life. Klinische Pädiatrie $2001213244-249$.

18 Muller HL, Gebhardt U, Faldum A, Emser A, Etavard-Gorris N, Kolb R \& Sorensen N. Functional capacity and body mass index in patients with sellar masses - cross-sectional study on 403 patients diagnosed during childhood and adolescence. Child's Nervous System 200521 539-545. (doi:10.1007/s00381-005-1166-9)

19 Rolland-Cachera MF, Cole TJ, Sempe M, Tichet J, Rossignol C \& Charraud A. Body mass index variations: centiles from birth to 87 years. European Journal of Clinical Nutrition 1991 45 13-21.

20 Wolff JE, Daumling E, Dirksen A, Dabrock A, Hartmann M \& Jurgens H. Munster Heidelberg Abilities Scale - a measuring instrument for global comparison of illness sequelae. Klinische Pädiatrie 1996208 294-298. 
21 Wolff JE, Huttermann U \& Askins MA. Quantifying health status outcomes in pediatric medulloblastoma patients. Anticancer Research 200727 523-529.

22 Bhat SR, Goodwin TL, Burwinkle TM, Lansdale MF, Dahl GV, Huhn SL, Gibbs IC, Donaldson SS, Rosenblum RK, Varni JW et al. Profile of daily life in children with brain tumors: an assessment of health-related quality of life. Journal of Clinical Oncology 200523 5493-5500. (doi:10.1200/JCO.2005.10.190)

23 Kosch A, Molenkamp G, Daumling E, Dirksen A, Jurgens H \& Wolff J. Assessment of independence in daily life in pediatric oncology by FMH-questionnaire. Klinische Pädiatrie 1998210 390-394.

24 Weiner HL, Wisoff JH, Rosenberg ME, Kupersmith MJ, Cohen H, Zagzag D, Shiminski-Maher T, Flamm ES, Epstein FJ \& Miller DC. Craniopharyngiomas: a clinicopathological analysis of factors predictive of recurrence and functional outcome. Neurosurgery 199435 1001-1010; discussion 1010-1011. (doi:10.1227/00006123199412000-00001)

25 Van Effenterre R \& Boch AL. Craniopharyngioma in adults and children: a study of 122 surgical cases. Journal of Neurosurgery 200297 3-11. (doi:10.3171/jns.2002.97.1.0003)

26 De Vile CJ, Grant DB, Kendall BE, Neville BG, Stanhope R, Watkins KE \& Hayward RD. Management of childhood craniopharyngioma: can the morbidity of radical surgery be predicted? Journal of Neurosurgery 1996 85 73-81. (doi:10.3171/jns.1996.85.1.0073)

27 Duff J, Meyer FB, Ilstrup DM, Laws ER Jr, Schleck CD \& Scheithauer BW. Long-term outcomes for surgically resected craniopharyngiomas. Neurosurgery 200046 291-302; discussion 302-305. (doi:10.1097/ 00006123-200002000-00007)

28 Bulow B, Attewell R, Hagmar L, Malmstrom P, Nordstrom CH \& Erfurth EM. Postoperative prognosis in craniopharyngioma with respect to cardiovascular mortality, survival, and tumor recurrence. Journal of Clinical Endocrinology and Metabolism 199883 3897-3904.

29 Pereira AM, Schmid EM, Schutte PJ, Voormolen JH, Biermasz NR, van Thiel SW, Corssmit EP, Smit JW, Roelfsema F \& Romijn JA. High prevalence of long-term cardiovascular, neurological and psychosocial morbidity after treatment for craniopharyngioma. Clinical Endocrinology 200562 197-204. (doi:10.1111/j.1365-2265.2004.02196.x)

30 Habrand JL, Ganry O, Couanet D, Rouxel V, Levy-Piedbois C, Pierre-Kahn A \& Kalifa C. The role of radiation therapy in the management of craniopharyngioma: a 25-year experience and review of the literature. International Journal of Radiation Oncology, Biology, Physics 199944 255-263. (doi:10.1016/S0360-3016(99)00030-9)

31 Muller HL. Childhood craniopharyngioma. Recent advances in diagnosis, treatment and follow-up. Hormone Research 200869 193-202. (doi:10.1159/000113019)

32 Regine WF, Mohiuddin M \& Kramer S. Long-term results of pediatric and adult craniopharyngiomas treated with combined surgery and radiation. Radiotherapy and Oncology 199327 13-21. (doi:10.1016/ 0167-8140(93)90039-B)

33 Muller HL, Gebhardt U, Pohl F, Flentje M, Emser A, Warmuth-Metz M, Kolb R, Calaminus G \& Sorensen N. Relapse pattern after complete resection and early progression after incomplete resection of childhood craniopharyngioma. Klinische Pädiatrie 2006218 315-320.

34 Hetelekidis S, Barnes PD, Tao ML, Fischer EG, Schneider L, Scott RM \& Tarbell NJ. 20-year experience in childhood craniopharyngioma. International Journal of Radiation Oncology, Biology, Physics 199327 189-195. (doi:10.1016/0360-3016(93)90227-M)

35 Kalapurakal JA, Goldman S, Hsieh YC, Tomita T \& Marymont MH. Clinical outcome in children with craniopharyngioma treated with primary surgery and radiotherapy deferred until relapse. Medical and Pediatric Oncology 200340 214-218. (doi:10.1002/mpo.10247)

36 Khafaga Y, Jenkin D, Kanaan I, Hassounah M, Al Shabanah M \& Gray A. Craniopharyngioma in children. International Journal of Radiation Oncology, Biology, Physics 199842 601-606. (doi:10.1016/S03603016(98)00257-0)

37 Lin LL, El Naqa I, Leonard JR, Park TS, Hollander AS, Michalski JM \& Mansur DB. Long-term outcome in children treated for craniopharyngioma with and without radiotherapy. Journal of Neurosurgery. Pediatrics 20081 126-130. (doi:10.3171/PED/2008/1/2/126)

38 Poretti A, Grotzer MA, Ribi K, Schonle E \& Boltshauser E. Outcome of craniopharyngioma in children: long-term complications and quality of life. Developmental Medicine and Child Neurology 200446 220-229. (doi:10.1111/j.1469-8749.2004.tb00476.x)

39 Scott RM, Hetelekidis S, Barnes PD, Goumnerova L \& Tarbell NJ. Surgery, radiation, and combination therapy in the treatment of childhood craniopharyngioma - a 20-year experience. Pediatric Neurosurgery 199421 (Suppl 1) 75-81. (doi:10.1159/000120866)

40 Visser J, Hukin J, Sargent M, Steinbok P, Goddard K \& Fryer C. Late mortality in pediatric patients with craniopharyngioma. Journal of Neuro-Oncology 2010100 105-111. (doi:10.1007/s11060-010-0145-5)

41 Cohen M, Bartels U, Branson H, Kulkarni AV \& Hamilton J. Trends in treatment and outcomes of pediatric craniopharyngioma, 1975-2011. Neuro-Oncology 201315 767-774. (doi:10.1093/neuonc/not026)

42 Regine WF \& Kramer S. Pediatric craniopharyngiomas: long term results of combined treatment with surgery and radiation. International Journal of Radiation Oncology, Biology, Physics 199224 611-617. (doi:10.1016/0360-3016(92)90705-M)

43 Bartlett JR. Craniopharyngiomas - a summary of 85 cases. Journal of Neurology, Neurosurgery, and Psychiatry 197134 37-41. (doi:10.1136/ jnnp.34.1.37)

44 Fahlbusch R, Honegger J, Paulus W, Huk W \& Buchfelder M. Surgical treatment of craniopharyngiomas: experience with 168 patients. Journal of Neurosurgery 199990 237-250. (doi:10.3171/jns.1999. 90.2.0237)

45 Pemberton LS, Dougal M, Magee B \& Gattamaneni HR. Experience of external beam radiotherapy given adjuvantly or at relapse following surgery for craniopharyngioma. Radiotherapy and Oncology 200577 99-104. (doi:10.1016/j.radonc.2005.04.015)

46 Rajan B, Ashley S, Gorman C, Jose CC, Horwich A, Bloom HJ, Marsh H $\&$ Brada M. Craniopharyngioma - a long-term results following limited surgery and radiotherapy. Radiotherapy and Oncology 199326 1-10. (doi:10.1016/0167-8140(93)90019-5)

47 Petito CK, DeGirolami U \& Earle KM. Craniopharyngiomas: a clinical and pathological review. Cancer 197637 1944-1952. (doi:10.1002/ 1097-0142(197604)37:4<1944::AID-CNCR2820370446>3.0.CO;2-)

48 Steno J, Bizik I, Steno A \& Matejcik V. Craniopharyngiomas in children: how radical should the surgeon be? Child's Nervous System 201127 41-54. (doi:10.1007/s00381-010-1330-8)

49 Erfurth EM, Holmer H \& Fjalldal SB. Mortality and morbidity in adult craniopharyngioma. Pituitary 201316 46-55. (doi:10.1007/s11102012-0428-2)

50 Muller HL, Faldum A, Etavard-Gorris N, Gebhardt U, Oeverink R, Kolb R \& Sorensen N. Functional capacity, obesity and hypothalamic involvement: cross-sectional study on 212 patients with childhood craniopharyngioma. Klinische Pädiatrie 2003215 310-314. (PMID: 14677094)

51 Muller HL, Bruhnken G, Emser A, Faldum A, Etavard-Gorris N, Gebhardt U, Kolb R \& Sorensen N. Longitudinal study on quality of life in 102 survivors of childhood craniopharyngioma. Child's Nervous System 200521 975-980. (doi:10.1007/s00381-004-1124-y)

Received 25 November 2014

Revised version received 21 January 2015

Accepted 3 February 2015 